Uludag Univ. J. Fac. Vet. Med.

32 (2013), 1: 53-57

\title{
Tavuk Karkas ve İşlenmiş Ürünlerinin Dekontaminasyonunda Güncel Yaklaşımlar
}

\author{
Mehmet Kurtuluş Cem ŞEN*
}

Geliş Tarihi: 22.10 .2013

Kabul Tarihi: 30.10 .2013

\begin{abstract}
Özet: Günümüzde modern kanatlı kesimhanelerinin varlığına ve bu işletmelerde uygulanan yüksek hijyen ve sanitasyon önlemlerine rağmen tavuk etine bağlı infeksiyonlar ve toksikasyonlar hala en önemli halk sağlığı problemlerinin başında gelmektedir. Tavuk eti ve işlenmiş ürünlerinin dekontaminasyonu konusunda farklı uygulamalar bulunmaktadır. Bu makalede kimyasal, fiziksel dekontaminasyon metotları ile bu metotların farklı kombinasyonlarını içeren yöntemler güncel bilgiler ışığında derlenmiştir.
\end{abstract}

Anahtar Kelimeler: Tavuk eti, halk sağlı̆̆, dekontaminasyon, gelişmiş oksidasyon teknolojisi.

\section{Updated Approaches in Decontamination of Chicken Carcass and Processed Products}

\begin{abstract}
Despite of the existence of modern poultry slaughterhouses and the advanced hygiene and sanitation precautions applied in these facilities, infections and toxications due to consumption chicken meat are still one of the most important public health problems. There are different applications for the decontamination of chicken carcass and processed products. In this article, methods including the various combination of chemical and physical decontamination methods were compiled in light of updated information.
\end{abstract}

Key Words: Chicken carcass, public health, decontamination, advanced oxidation technology.

\section{Giriş}

Tavuk eti besleyici değerinin yüksek olması buna karşın ekonomik yönden daha kolay ulaşılabilir olması günümüzde nedeni ile en fazla tüketilen hayvansal gıdaların başında gelmektedir. Tavuk eti yüksek protein ve düşük yağ içeriğine sahiptir ve doymamış yağ asidi yönünden de uygun kompozisyona sahiptir. $\mathrm{Bu}$ özellikler tavuk etinin besleyici değerini arttırmaktadır. Günümüzde tavuk etine olan yüksek talep ile birlikte modern tavuk işletmeleri ve kesimhanelerinin sayısı da gittikçe artmaktadır. Buna karşın kanatlı kesimhaneleri birim zamanda çok sayıda hayvan kesilmesi ve kesilen hayvanların kesim hattı boyunca birçok farklı du- rakta işlem görmesi (kesim, tüy islatma-yolma, iç organların çıkarılması vb.) nedeni ile her zaman yüksek kontaminasyon riski taşımaktadır. Tavuk etinin ayrıca farklı işlenmiş ürünler şeklinde tüketildiği de düşünüldügünde kontaminasyon riskinin artması kaçınılmazdır. Diğer yandan tavuk eti gerek içeriği ve gerekse kesim, işleme ve depolama sürecindeki hazırlayıcı faktörler nedeni ile birçok mikroorganizma için uygun bir ortam sağlamaktadır. Bu mikroorganizmaların bir kısmı nonpatojenik olup tavuk karkaslarında ve ürünlerinde bozulmalara neden olurken, bir kısmı da patojenik ve toksijenik karakterde olup bunları tüketen insanlarda çeşitli infeksiyonlara ve intoksikasyonlara yol açmaktadır. Özellikle halk sağlığı açısından önem

\footnotetext{
* Doç.Dr., Uludağ Üniversitesi Veteriner Fakültesi, Besin Hijyeni ve Teknolojisi Anabilim Dalı, Görükle Kampüsü, 16059, Bursa, Türkiye.mkcsen@uludag.edu.tr
} 
taşıyan Salmonella, Campylobacter, Listeria gibi patojen mikroorganizmalar tavuk etlerindeki en önemli risk faktörleridir ${ }^{6,20,21}$.

Sağliklı hayvan-sağliklı gıda zinciri kapsamında tavuk karkas ve işlenmiş ürünlerinin dekontaminasyonu amacı ile farklı yöntemler kullanılmaktadır. Temel olarak bu yöntemler fiziksel, kimyasal ve biyolojik tekniklerden oluşmaktadır ${ }^{8,16,18}$. Ayrıca bu yöntemlerin farklı kombinasyonları da aynı amaçla kullanılmakta$\mathrm{d}_{1} \mathrm{r}^{2,31}$.

Tavuk karkaslarının kimyasal dekontaminasyonu amacı ile çeşitli kimyasal maddeler kullanılmaktadır. Bunlar arasında asetik asit, laktik asit, sitrik asit gibi organik bazlı kimyasal maddeler yanı sıra klor ve klor dioksit, hipoklorid, sodyum hipoklorid, sodyum klorid, monokloramin gibi klor bazlı bileşikler ve trisodyum fosfat gibi fosfat bazlı bileşikler bulunmaktadır. Kimyasal dekontaminasyon işlemleri bakterilerin hücre membranlarını, hücresel içeriklerini ve fizyolojik fonksiyonların hedef alarak bakterisidal etki göstermektedir. Bu alanda çok sayıda kimyasal bileşik bulunmasına karşın günümüzde organik asitler, klorlu bileşikler ve trisodyum fosfat kanatlı endüstrisinde en fazla kullanım alanı olanlarıdır ${ }^{19,27}$. Kesimhanelerde özellikle organik asitler, trisodyum fosfat ve farklı bileşenleri ile tavuk karkaslarındaki bakteri sayıs1nın önemli ölçüde düşürüldüğü bildirilmekte$\operatorname{dir}^{14,15}$. Ancak organik asitlerle yapılan işlemlerde kullanılan bileşiklerin içeriklerinin ve uygulama sürelerinin çok hassas şekilde dengelenmesi gerekmektedir. Aksi halinde karkas derisinde istenmeyen koku ve renk değişikliklerine yol açabilirler ${ }^{3,7}$.

Fiziksel dekontaminasyon yöntemleri arasında su bazlı uygulamalar (su ve su buharı uygulamaları, basınçlı su uygulamaları, elektrolize su uygulamaları ve ozonlanmış su uygulamalar1), iyonizan radyasyon, ultra sonik uygulamalar, soğutma, dondurma işlemleri bulunmaktadır. Bunlar arasında tavuk karkaslarının dekontaminasyonu amacı ile en fazla kullanım alanı bulanlar su bazlı uygulamalar ile buhar uygulamalarıdır. Özellikle sicak su ve buhar uygulamaları sonrasında derideki bakteri yükünün önemli ölçüde azaldığ bildirilmektedir $^{22,29}$. Tompkins ve ark. $^{32}$, kaynayan suya $\left(\sim 95^{\circ} \mathrm{C}\right)$ daldırma yöntemi ile tavuk karkas derisindeki aerobik bakteri sayısının önemli ölçüde azaldığını ve bu tavuklardan derileri uzaklaştırılarak hazırlanan işlenmiş gıdalarda da patojen kontaminasyon riskinin minimize edildiğini bildirmişlerdir.
Günümüzde gıdaların mikrobiyel yüklerini en aza indirmek amacı ile kimyasal ve fiziksel yöntemlerin farklı kombinasyonlarını içeren yeni stratejiler geliştirilmektedir. Bunun en tipik örneği İleri Gelişmiş Oksidasyon Teknolojisi (Advanced Oxidation Technology- AOT) olarak tanımlanan, ozon, ultraviole 1şın ve hidrojen peroksit, titanyum dioksit bileşenlerinin farklı kombinasyonlarda kullanımıdır ${ }^{5,33}$. Siv1 ve gaz fazdaki oksidasyon yöntemlerini kapsayan AOT, yüksek reaktiviteye sahip oksijen ürünlerinin ve hidroksil radikallerinin açığa çıkması ve bu ürünlerin mikroorganizmaları farklı yollardan inaktive etmesi esasına dayanmaktadır. Hidroksil radikalleri güçlü ve non-selektif kimyasal oksidanlardır ve birçok organik bileşik ile çok hızlı etkileşime girer. Ayrıca organik kontaminantları substratların tipine bağlı olarak su, karbondioksit ve mineral tuzlara kadar tamamen okside eder. Diğer oksidanlarla karşılaştırıld1ğında hidroksil radikallerinin oksidasyon gücünün fazla olduğu görülmektedir (Tablo 1).

\section{Tablo 1. Bazı oksidanların relatif oksidasyon güçleri (Oppenlander 2003)}

Table 1. Relative oxidation power of some oxidizing species (Oppenlander 2003)

\begin{tabular}{|lc|}
\hline Oksidanlar & $\begin{array}{c}\text { Relatif Oksidasyon Gücü } \\
\text { (Klor=1) }\end{array}$ \\
Hidroksil Radikalleri & 2.05 \\
Atomik Oksijen & 1.78 \\
Ozon & 1.52 \\
Hidrojen Peroksit & 1.31 \\
Permanganat & 1.24 \\
Klor & 1.00 \\
\hline
\end{tabular}

AOT su, hava, gıda ve yağ endüstrisi gibi birçok farklı alanda mikrobiyel dekontaminasyon amacı ile kullanılmaktadır. Bu teknoloji içinde yer alan Photohydroionization ${ }^{\mathrm{TM}}\left(\mathrm{PHI}^{\mathrm{TM}}\right)$ ise UV-C /ozon bileşenlerini kullanan ve günümüzde geniş uygulama alanına sahip ticari bir markayı tanımlamaktadır. $\mathrm{PHI}^{\mathrm{TM}}$ özellikle gıda sektöründe, gıda ürünlerinin veya gıda ile temas eden işlem alanlarının yüzey dekontaminasyonu amac1 ile kullanılmaktadır ${ }^{9} 10$. Saini ${ }^{26}$ tarafindan yapılan bir çalışmada işlenmiş hindi eti ürünleri deneysel olarak Listeria monocytogenes ile kontamine edilmiş ve $\mathrm{PHI}^{\mathrm{TM}}$, $n i n$ bu ürünlerin dekontaminasyonundaki etkinliği incelenmiştir. Çalışmada $\mathrm{PHI}^{\mathrm{TM}}$ ile $5 \mathrm{~d}$. uygulama sonrasında işlenmiş hindi etinde Listeria monocytogenes' in 2.16 and $2.52 \log$ CFU/örnek düzeyinde azaldı- 
ğ1 saptanmıştır. $\mathrm{Bu}$ teknoloji hızlı reaksiyon oluşturmas1, kimyasal madde içermemesi, organik kontaminantlarda tam oksidasyon oluşturarak yüksek düzeyde etkinlik ve düşük toksisite, düşük maliyet gibi avantajlara sahiptir. Bu yöntemde gıda maddeleri yüksek yoğunlukta ultraviole 1şın içeren ve özel metal kaplı bir tünel hattından geçirilmektedir. Düşük düzeyde ozon içeren ve nemli olan bu tünel ortamında şekillenen oksidatif reaksiyonlar sonucunda açığa çıkan hidroksil radikalleri ortamdaki organik maddeleri yıkımlamaktadırlar. Reaksiyonun ardından ortamda sadece zararsız oksijen ve hidrojen iyonları kalmaktadır. Diğer yandan $\mathrm{PHI}^{\mathrm{TM}}$ teknolojisinde kullanılan UV-C ozon lambaları temas ettikleri yüzeyde etkisini gösterdikten sonra hiçbir radyoaktif kalıntı bırakmamaktadır. Böylece özellikle tüketicilerde tedirginlik yaratan herhangi bir risk taşımamaktadır ${ }^{9,26}$ (Şekil 1). PHI ${ }^{\mathrm{TM}}$ kapsamında yer alan ozon yüksek oksidasyon kapasitesine sahiptir ve bakterilerde ozona karşı direnç gelişimi söz konusu değildir. Bu nedenle günümüzde klorlu bileşikler gibi çeşitli kimyasal maddelere karşı bakterilerde gelişen direnç riski bu teknolojide bulunmamaktadır ${ }^{1}$.

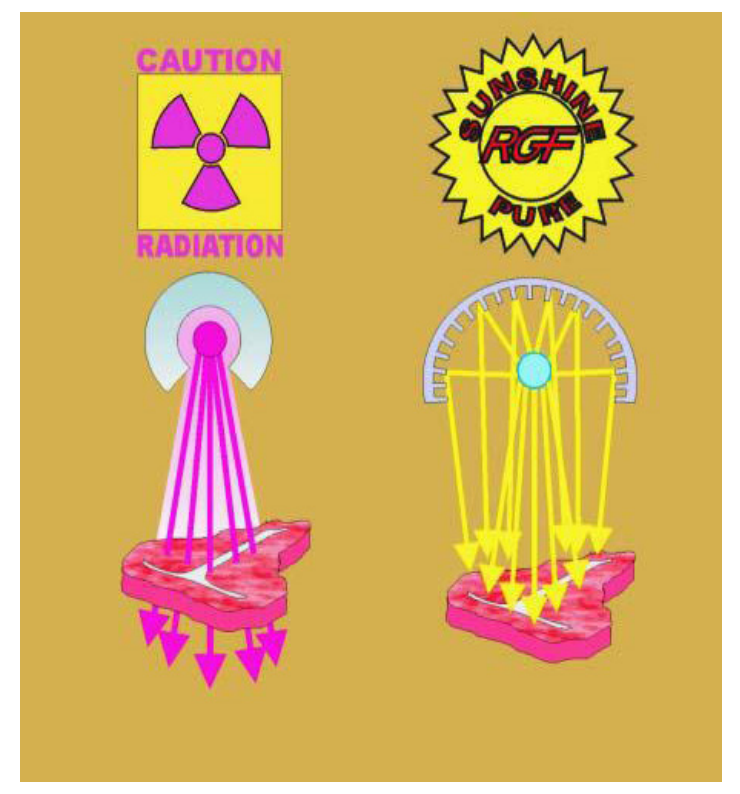

Şekil 1. Photohydroionization ${ }^{T M}$ teknolojisinde iyonizan radyasyonun yüzey etkisi (Fink 2004)

Figure 1. Surface effect of ionizing radiation in the Photohydroionization ${ }^{T M}$ Technology

(Fink 2004)

AOT kapsamında yer alan kombinasyonlardan biri de ultraviole/titanyum dioksit bileşenlerini kullanan Photocatalytic oxidation (PCO) teknolojisidir ${ }^{12,13}$. Bu sistem ile su ve atık suların dezenfeksiyonu yanı sıra bakteri, virus ve protozoonların inaktivasyonu konusunda çeşitli çalışmalar bulunmaktadır ${ }^{4,12,24,30}$. Tavuk karkaslarında dekontaminasyon amacı ile PCO tekniğinin kullanımı henüz yeterince incelenmemiş olmasına karşın, Sen, M.K.C. ${ }^{28}$ tarafından yapılan bir çalışmada PCO işlemi ile tüm örnekleme zamanlarında (3., 5., 7. ve 12. saatler) tavuk karkaslarındaki toplam aerobik bakteri sayısında lineer bir azalma gözlendiği ve PCO'nun kanatlı kesimhanelerinde karkasların yüzey dekontaminasyonunda yeni bir yaklaşım olarak dikkate alınabileceği vurgulanmıştır.

Biyolojik dekontaminasyon amacı ile günümüzde bakteriyofaj ve bakteriosinleri içeren bazı uygulamalar bulunmaktadır. Bakteriyofajlar konakçı spesifitesi yüksek ve uygulaması güvenli yöntem olarak bildirilmektedir ${ }^{11,17}$. Ancak bakteriyofajların tavuk karkaslarında dekontaminasyon amacı ile kullanımı oldukça sınırlıdir.

\section{Sonuç}

Günümüzde insan beslenmesinde büyük önem taşıyan tavuk eti ve işlenmiş ürünleri beraberinde önemli sağlık risklerini de barındırmaktadır. Sağlıklı hayvan sağlıklı gıda zincirinin son halkalarını oluşturan kanatlı kesim ve işleme basamaklarında hijyen ve sanitasyon kurallarına dikkat edilmesi kritik öneme sahiptir. Bu yazıda tavuk karkas ve işlenmiş ürünlerinin dekontaminasyonunda uygulanan yöntemler ve bu konudaki güncel yaklaşımlar ele alınmıştır.

Gelişmiş Oksidasyon Teknolojisi, fiziksel ve kimyasal dekontaminasyon tekniklerinin farklı kombinasyonlarını içeren uygulamalardır ve geleneksel yöntemlere göre bazı üstün özelliklere sahiptir. Bu teknoloji kanatl kesimhanelerinde özellikle soğuk depo ortamında uygulanabilir olup, pratik, hızlı ve güvenli olması ile dikkati çekmektedir. Ülkemiz için henüz yeni ve uygulama alanı kisitlı olan AOT, gelecekte gıda sektörü de dahil olmak üzere birçok alanda daha geniş bir kullanıma sahip olacaktır.

\section{Kaynaklar}

1. Anonymous. 2012. Ozone use for surface sanitation.

http://www.ozonesolutions.com/Ozone_use_for_ Surface_Sanitation.html

2. Bacon, R.T., Belk, K.E., Sofos, J.N., Clayton, R.P., Reagan, J.O., Smith, G.C., 2000. Microbial 
population on animal hides and beef carcasses at different stages of slaughter in plants employing multiple-squential interventions for decontamination. J. Food Protec., 63, 1080-1086.

3. Bilgili, S.F., Conner, D.E., Pinion, J, L., Tamblyn, K.C., 1998. Broiler skin color as affected organic acid: influence concentration and method of application. Poultry Sci., 77, 751-757.

4. Cho, M., Chung, H., Choi, W., Yoon, J., 2004. Linear correlation between inactivation of E.coli and $\mathrm{OH}$ radical concentration in $\mathrm{TiO}_{2}$ photocatalytic disinfection. Water Res., 38, 1069-1077.

5. Comninellis, C., Kapalka, A., Malato, S., Parsons, S.A., Poulios, I., Mantzavinos, D., 2008. Perspective: Advanced oxidation processes for water treatment: advances and trends for R\&D. J. Chem. Technol. Biotechnol., 83, 769-776.

6. Cook, A., Odumeru, J., Lee, S., Pollari, F., 2012. Campylobacter, Salmonella, Listeria monocytogenes, Verotoxigenic Escherichia coli, and Escherichia coli prevalence, enumeration, and subtypes on retail chicken breasts with and without skin. J. Food Prot., 75, 34-40.

7. Dickens, J.A., Lyon, B.G., Whittemore, A.D., Lyon, C.D., 1994. The effect of acetic acid dip on carcass appearence, microbiological quality and cooked breast meat texture and flavor. Poultry Sci., 73, 576-581.

8. Dincer, H. A., Baysal, T., 2004. Decontamination techniques of pathogen bacteria in meat and poultry. Crit. Rev. Microbiol., 30, 197-204.

9. Fink, R.G., 2012. RGF's advanced oxidation technology.

http://www.rgf.com/documents/AOT_book.pdf

10. Fink, R.G., Ellis, W., Hart, J.A., Pearsall, C., Rinehimer, S., 2011. A review of the efficacy, safety, and perception of photohydroionization/ advanced oxidation as an anti-microbial versus traditional chlorine and radiation. http://www.rgf.com/published article detail.cfm

11. Greer, G., 2005. Bacteriophage control of foodborne bacteria, J. Food Prot., 68, 1102-1111.

12. Gumy, D., Morais, C., Bowen, P., Pulgarin, C., Giraldo, S., Hajdu, R., Kiwi, J., 2006. Catalytic activity of commercial of $\mathrm{TiO}_{2}$ powders for the abatement of the bacteria $(E$. coli) under solar simulated light: influence of the isoelectric point. Appl. Catal. B., 63, 76-84.

13. Heponiemi, A., Lassi, U., 2012. Advanced oxidation processes in food industry wastewater treatment - A review, Food Industrial Processes Methods and Equipment, Dr. Benjamin Valdez (Ed.), 313-338.

http://www.intechopen.com/books/food-

industrial-processesmethods-and-

equipment/advanced-oxidation-processes-infood-industry-wastewater-treatment-a-review.
14. Hinton, A. Jr., Ingram, K.D., 2005. Microbicidal activity of tripotassium phosphate and fatty acid towards spoilage and patogenic bacteria associated with poultry. J. Food Prot., 68, 1462-1466.

15. Hinton, A. Jr., Cason, J. A., 2008. Bacterial flora of processed broiler chicken skin after successive washings in mixtures of potassium hydroxide and lauric acid. J. Food Prot., 71, 1707-1713.

16. Huffmann, R.D., 2002. Current and future technologies for the decontamination of carcasses and fresh meat. Meat Sci., 62, 285-294.

17. Hudson, J.A., Billington, C., Carey-Smith, G., Greening, G., 2005. Bacteriophages as biocontrol agents in food. J. Food Prot., 68, 426-437.

18. Koohmaraie, M., Arthur,T.M., Bosilevac, J.M., Guerini, M., Schackelford, S.D., Wheeler, T.L., 2005. Post-harvest interventions to reduce/eliminate pathogens in beef. Meat Sci., 71, 7991.

19. Loretz, M., Stephan, R, R., Zweifel, C., 2010. Antimicrobial acticvity of decontamination treatments for poultry carcasses: a literature survey. Food Control, 21, 791-804.

20. Mahgoub, S., Sitohy, M., 2013. Comparative prevalence of pathogenic and spoilage microbes in chicken sausages from Egypt and Greece. Health., 5, 274-284.

21. Mead, G., 2004. Poultry meat processing and quality, Woodhead Publishing Limited, UK.

22. Northcutt, J. K., Smith, D. P., Musgruve, M .T., Ingram, K. D., Hinton, A. Jr., 2005. Microbiological impact of spray washing broiler carcasses using different chlorine concentration and water temperatures. Poultry Sci., 84, 1648-1652.

23. Oppenlander, T., 2003. Photochemical purification of water and air (Advanced Oxidation Processes (AOPs): Principles, Reaction Mechanisms, Reactor Concepts), Wiley-VCH.

24. Rincón, A.G., Pulgarin, C., 2004. Effect of pH, inorganic ions, organic matter and $\mathrm{H}_{2} \mathrm{O}^{2}$ on E. coli $\mathrm{K} 12$ photocatalytic inactivation by $\mathrm{TiO}_{2}$ : implications in solar water disinfection. Appl. Catal. B., 51, 283-302.

25. Rodriguez de Ledesma, A.M., Riemann, H.P., Farver, T.B., 1996. Short-time treatment with alkali and/or hot water to remove common pathogenic and spoilage bacteria from chicken wing skin. J. Food Prot., 59, 746-750.

26. Saini, J.K., 2012. Control strategies for Listeria monocytogenes in ready-to-eat foods and on food contact surfaces. PhD Thesis, Kansas State University, Manhattan Kansas.

27. Sallam, K. I., Samejima, K., 2004. Effects of trisodium phosphate and sodium chloride dipping on the microbial quality and shelf life of refrigerated tray-packaged chicken breasts. Food Sci. Biotechnol., 13, 425-429. 
28. Sen, M.K.C. 2013, Effect of photocatalytic oxidation on aerobic bacteria counts of broiler carcass, J. Anim. Vet. Adv., (Baskıda).

29. Sinhamahapatra, M., Biswas, S., Das, A.K., Bhattacharyya, D., 2004. Comparative study of different surface decontaminants on chicken quality. Br. Poult. Sci., 45, 624-630.

30. Sirimahachai, U., Phongpaichit, S., Wongnawa, S., 2009. Evaluation of bactericidal activity of $\mathrm{TiO}_{2}$ photocatalysts: a comparative study of laboratory-made and commercial $\mathrm{TiO}_{2}$ samples. Songklanakarin J. Sci. Technol., 31, 517-525.

31. Stopforth, J.D., O’Connor, R., Lopes, M., Kottapalli, B., Hill, W.E., Samadpour, M., 2007. Vali- dation of individual and multiple sequential interventions for reduction of microbial population during processing of poultry carcasses and parts. J. Food Prot., 70, 1393-1401.

32. Tompkins, N. M., Avens, J. S., Kendall, P. A., Salman, M.D., 2008. Effect of boiling water carcass immersion on aerobic bacteria counts of poultry skin and processed ground poultry meat. Zoonoses Public Hlth., 55, 235-241.

33. Vogelpohl, A., S. M. Kim., 2004. Advanced oxidation processes (AOPs) in wastewater treatment. J. Ind. Eng. Chem., 10, 33-40. 
